\title{
Consequence modelling of hypothetical post-closure criticality events for spent fuel disposal
}

\author{
R. M. Mason ${ }^{1, *}$, J.K. Martin ${ }^{1}$, P. N. SMith ${ }^{1}$ and R. J. Winsley ${ }^{2}$
}

1 Amec Foster Wheeler, Kings Point House, Queen Mother Square, Poundbury, Dorchester DT1 3BW, UK.

2 Radioactive Waste Management, Curie Avenue, Building 587, Harwell, Oxford OX11 0RH, UK

[Received 17 October 2014; Accepted 17 June 2015; Associate Editor: Nick D. Bryan]

\section{ABSTRACT}

In support of the Radioactive Waste Management (RWM) safety case for a geological disposal facility (GDF) in the UK, there is a regulatory requirement to consider the likelihood and consequences of nuclear criticality. Waste packages are designed to ensure that criticality is not possible during the transport and operational phases of a GDF and for a significant period post-closure. However, over longer post-closure timescales, conditions in the GDF will evolve.

For waste packages containing spent fuel, it can be shown that, under certain conditions, package flooding could result in a type of criticality event referred to as 'quasi-steady-state' (QSS). Although unlikely, this defines a 'what-if' scenario for understanding the potential consequences of post-closure criticality. This paper provides an overview of a methodology to understand QSS criticality and its application to a spent fuel waste package.

The power of such a hypothetical criticality event is typically estimated to be a few kilowatts: comparable with international studies of similar systems and the decay heat for which waste packages are designed. This work has built confidence in the methodology and supports RWM's demonstration that post-closure criticality is not a significant concern.

Keywords: geological disposal, post-closure, spent fuel, criticality.

\section{Introduction}

RadioACTIVE Waste Management (RWM), a wholly owned subsidiary of the Nuclear Decommissioning Authority (NDA), is responsible for implementing geological disposal of the UK's higher-activity waste inventory. At present in the UK a site for a Geological Disposal Facility (GDF) has not been identified, and RWM has produced an initial 'generic' Disposal System Safety Case (DSSC) to communicate the safety arguments for geological

* E-mail: robert.mason@amecfw.com DOI: $10.1180 /$ minmag.2015.079.6.25 disposal using a range of illustrative disposal concepts and paired host geologies (Nuclear Decommissioning Authority, 2010a).

A GDF will be required to include the disposal of a significant amount of fissile material. If not managed appropriately, this fissile material could, hypothetically and under very specific conditions, lead to an unplanned sustained neutron chain reaction ('criticality'). Because of this, demonstration of criticality safety forms an important part of the DSSC. The Environment Agency (2009) Guidance on Requirements for Authorisation (GRA) for a GDF requests a demonstration that "the possibility of a local accumulation of fissile material such as to produce a neutron chain reaction
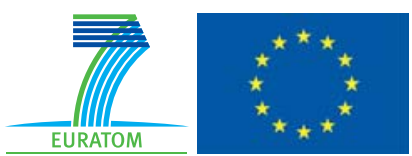

The publication of this research has been funded by the European Union's European Atomic Energy Community's (Euratom) Seventh Framework programme FP7 (2007-2013) under grant agreements $n^{\circ} 249396$, SecIGD, and n³23260, SeclGD2. 
is not a significant concern". Furthermore, the GRA states that the "environmental safety case should also investigate, as a 'what-if' scenario, the impact of a postulated criticality event on the performance of the disposal system". The environmental safety case (Nuclear Decommissioning Authority, 2010b) is an important component of RWM's DSSC. A 'what-if' criticality scenario is taken to be an assumed sequence of events whereby, within a localized volume of a GDF or the surrounding host rock, a critical configuration of fissile materials is reached.

Waste packages can be designed to ensure that criticality is not possible during the transport and operational phases of a GDF, and for a significant period post-closure (Nuclear Decommissioning Authority, 2010c). Over longer times, however, waste packages may degrade so that groundwater may enter the packages or, coupled with geochemical processes such as dissolution and sorption, could transport fissile nuclides within regions of the GDF or surrounding geology. These evolving systems mean that criticality cannot be ruled out completely. Underpinning knowledge is therefore needed to demonstrate: an understanding of conditions under which criticality could occur; the likelihood of such conditions being reached; and the consequences of criticality for GDF performance if post-closure criticality did occur.

The work presented here forms a part of RWM's post-closure criticality safety research programme that provides the supporting knowledge base. The focus for this paper is understanding the consequences of a hypothetical criticality event resulting from the disposal of spent fuel from a pressurized water reactor (PWR), including how detailed simulation of critical systems supports the understanding. A broader overview of the RWM-led research programme, discussing both the likelihood and consequences of post-closure criticality has been described by Winsley et al. (2015).

\section{Overview of hypothetical post-closure criticality}

In a system containing fissile material, the fissile nuclides such as uranium-235 $\left({ }^{235} \mathrm{U}\right)$ and plutonium-239 $\left({ }^{239} \mathrm{Pu}\right)$ can emit neutrons. The neutrons released may cause another fissile nuclide to split into two smaller nuclides, accompanied by the release of more neutrons - a process known as nuclear fission. The process of fission also releases energy as radiation and heat. Neutrons may be lost through absorption in non-fissile nuclides, or may leave the fissile part of the system to be absorbed in surrounding materials (leakage).

Under certain conditions a self-sustaining chain fission reaction can be established. Those conditions include a suitable: combination of fissile mass, density, volume, shape; fissile concentration and enrichment (the weight fraction of the fissile nuclide ${ }^{235} \mathrm{U}$ in uranium); and presence of neutron moderators (which slow down neutrons), absorbers (which absorb neutrons), and reflectors (which reduce the leakage of neutrons). At the point where the chain reaction becomes self-sustaining the system is said to be critical and there is a balance between the number of neutrons being produced by fission and the number being lost by absorption and leakage.

Mathematically, a measure of how close a system is to being critical is defined as $k_{\text {effective }}$, the ratio of the rate of neutron production (by fission) to the rate of neutron losses (by absorption plus leakage). At the point of criticality, $k_{\text {effective }}$ is equal to unity. For super-critical systems $k_{\text {effective }}>1$; in sub-critical systems it is $<1$.

Given the number of conditions required for a critical configuration, the presence of fissile materials alone does not mean that a critical configuration can occur, nor that it is likely to occur. Indeed, for any wastes emplaced in a GDF, the initial distribution of fissile (or other) materials would need to change significantly from the sub-critical emplacement. Such changes will only be possible once sufficient time has passed that the engineered barriers in a GDF are significantly degraded. Recent research led by RWM has considered the likelihood of criticality extensively for a wide range of waste packages and illustrative disposal concepts and demonstrates clearly that any criticality is either not possible (e.g. due to insufficient fissile material), or has a low likelihood of occurrence (Hicks and Baldwin, 2014; Winsley et al., 2015).

\section{Methodology to understand the consequences of hypothetical criticality}

The methodology to understand the consequences of hypothetical post-closure criticality follows some distinct stages: (1) how, hypothetically, could a critical system arise?; (2) how could the critical system evolve?; and (3) what would the local consequences be?

If the answer to the first question is that criticality is not possible, or the likelihood of occurrence is so 
vanishingly small as to be considered not credible, then answering the second two questions can be judged unnecessary.

In the unlikely event that a sustained neutron chain reaction were to begin by chance in a GDF (i.e. the system were to become critical or supercritical) heat would be released and so, locally, the temperature would increase. The effect of a change in temperature on the value of $k_{\text {effective }}$ determines the nature of the criticality transient. One type of transient criticality is a potentially long-lived but low-power transient, sustained by competing processes maintaining a just-critical $\left(k_{\text {effective }}=1\right)$ system. Such a transient can result from a critical system with negative temperature feedback, where the temperature increase acts to reduce $k_{\text {effective, }}$ but another process acts to increase $k_{\text {effective }}$. Another type of transient criticality is a short-lived but energetic transient and can result from a critical system with positive temperature feedback, where $k_{\text {effective }}$ increases with a rise in temperature. These are termed Quasi-Steady-State (QSS) and Rapid Transient (RT) criticality events, respectively, and could potentially have very different physical consequences for a GDF (Mason et al., 2012a). A hypothetical post-closure criticality event would not, necessarily, evolve as a QSS or RT event. Complex dependencies of $k_{\text {effective }}$ with evolving temperature, fissile composition and neutron moderation, for example, could lead to changes in whether the system has negative or positive temperature feedback as the criticality evolves. For the purposes of scoping studies, such variations have not been considered in detail; on the basis that QSS or RT analysis should bound the local consequences of criticality.

Understanding transient criticality is important in addressing the 'what-if' scenario of the GRA, and RWM has therefore developed and documented bespoke software models to understand QSS and RT criticality (Mason and Smith, 2013; Smith and Mason, 2015), and has applied the models to a wide range of hypothetical post-closure criticality events for different waste types and different illustrative disposal concepts. The model development initially focused on the disposal of intermediate-level waste (ILW) in a GDF within a higher-strength rock (Mason et al. 2009, 2010), but has recently been extended to cover a much broader range of higheractivity wastes and different illustrative disposal concepts (Mason et al., 2014; Mason and Smith 2015a,b).

This paper focuses on applying the methodology and the model for hypothetical QSS transient criticality events following PWR spent fuel disposal. Use of the methodology and models for hypothetical RT criticality events is not necessary for PWR spent fuel disposal: because the fuel is predominantly uranium (although irradiated fuel will contain some plutonium) it is possible to demonstrate that $k_{\text {effective }}$ will decrease with increasing temperature (Mason and Smith, 2015b).

\section{Overview: hypothetical post-closure criticality from spent-fuel disposal}

An illustrative disposal concept for PWR spent fuel in a higher-strength rock is described by Winsley et al. (2015). The waste package contains four fuel elements from a PWR in a square array within a nominally dry cylindrical copper and iron waste container. The waste package contains some void space. For geological disposal the waste package is placed into a vertical deposition channel within a GDF, surrounded by bentonite (a clay-based material that swells when wet). Once a number of packages have been emplaced, the GDF is backfilled.

PWR fuel is designed to sustain a critical system in the presence of water (given a sufficient number of fuel elements and under carefully controlled conditions) within a nuclear reactor; the likelihood of post-closure criticality is therefore not obviously zero should water ingress into a package occur. The configuration of a flooding package has therefore been considered as one of several 'what-if' scenarios for post-closure criticality (Mason et al., 2014; Mason and Smith, 2015b).

When resident in a nuclear reactor, the uranium oxide fuel (initially uranium with an enrichment of up to $5 \%$ ) will undergo fission, releasing fission products and neutrons. Over time the composition of the uranium will change as an increasing number of the ${ }^{235} \mathrm{U}$ atoms undergo fission. Furthermore, neutron capture may lead to the production of uranium-236 $\left({ }^{236} \mathrm{U}\right)$ from neutron capture in ${ }^{235} \mathrm{U}$, and ${ }^{239} \mathrm{Pu}$ from neutron capture in uranium-238 $\left({ }^{238} \mathrm{U}\right)$, for example. This process is known as nuclear fuel irradiation or 'burn-up' and is measured in units of gigawatt days per tonne of uranium $(\mathrm{GWd} / \mathrm{Te})$. Once the burn-up is sufficiently high, the fuel will no longer be able to sustain a critical system in the reactor and will be removed as spent fuel. For PWR fuel the average burn-up of spent fuel is taken to be $55 \mathrm{GWd} / \mathrm{Te}$. However, it could be lower if fuel was removed from the reactor earlier in its productive life-cycle. 
Following the methodology outlined above, this paper presents analysis to show: (1) the conditions under which a package containing PWR spent fuel could, hypothetically, become critical if it were to flood with water; and (2) how such a critical system could evolve, and what the local consequences would be.

Furthermore, a brief comparison of the results with those of other international studies of postclosure criticality is given.

\section{Analysis: critical configurations}

When PWR fuel is resident in a nuclear reactor, the uranium fuel does not burn-up uniformly along the length of a fuel element due to axial variations in the neutron flux (number of neutrons per unit area per unit time) and the power profile across the reactor core. This means that although the fresh (zero burn-up) fuel placed in a reactor is uniform along its length, the fuel will have a lower burn-up (or greater uranium enrichment) at the ends than in the centre when it is removed. Uranium enrichment has a strong influence on whether a system can become critical, and therefore the axial burn-up profile is important in determining whether irradiated fuel could become critical in the presence of water.

The WIMS software package provides detailed reactor physics methods, including software modules, to analyse nuclear fuel burn-up (Newton et al., 2008). WIMS was therefore used to calculate an axial burn-up profile for a PWR fuel element, starting from a non-irradiated uranium enrichment of $5 \%$ by weight (5.06 atom.\%). By dividing the fuel element length into twenty sections of equal length, with symmetry about the centre so that results are only produced for ten sections, a representative axial burn-up profile was calculated as a function of average burn-up for the entire fuel element. When the average burn-up is $55 \mathrm{GWd} / \mathrm{Te}$, the fraction of fissile isotopes of uranium and plutonium is $\sim 2 \%$ over most of the fuel element, but is $\sim 2.7 \%$ at the ends of the fuel element (Fig. 1). The non-irradiated fuel $(0 \mathrm{GWd} / \mathrm{Te})$ is slightly $>5 \%$ in Fig. 1 as it shows the fraction of atoms rather than wt.\%. Further analysis, as illustrated in Fig. 2, shows how the fraction of fissile isotopes reduces further if a cooling period, $T$, is included in the modelling. Over this period, no further fuel burn-up occurs, but fissile isotopes can become non-fissile isotopes as a result of radioactive decay.

The irradiated fuel compositions from WIMS can be used as inputs to criticality software to understand whether criticality could occur, should a fuel package become flooded in a GDF postclosure. Using a detailed geometrical representation of the illustrative waste package for PWR fuel, including representing each individual fuel pin within the fuel elements, calculations were undertaken using the $M O N K{ }^{\circledR}$ criticality software

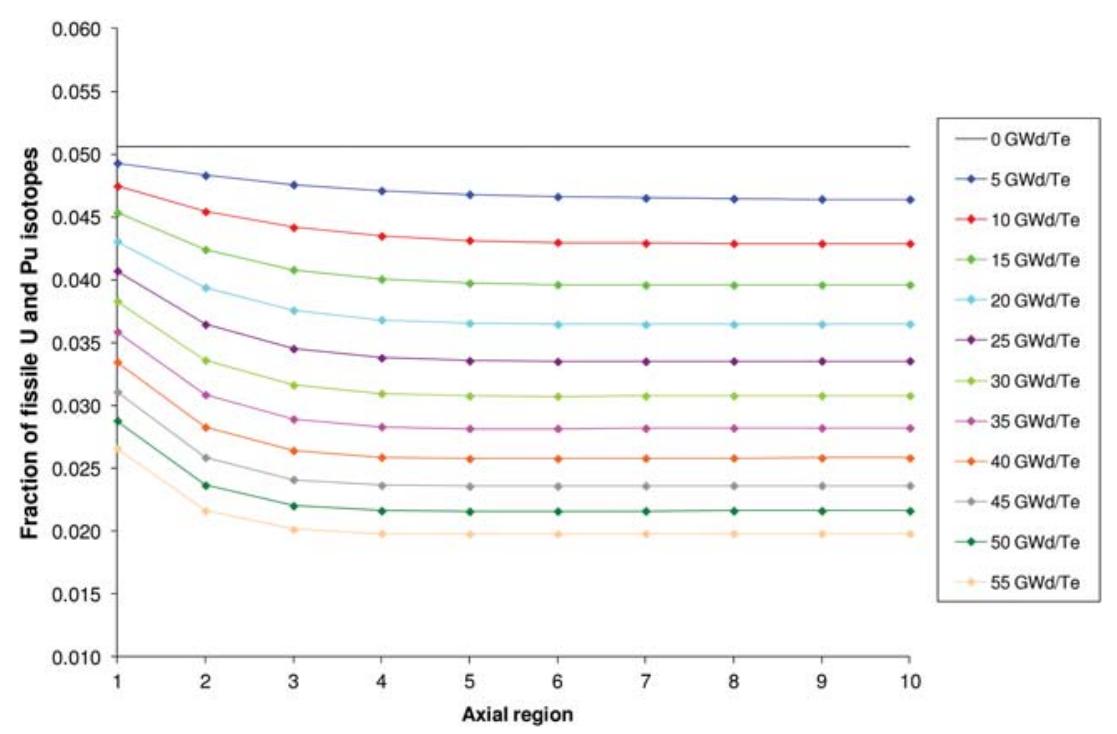

FIG. 1. Variation of the fraction of fissile uranium and plutonium nuclides at different levels of average burn-up. 
(Richards et al., 2014) for spent fuel with different values for the average fuel burn-up, some different cooling periods (for the highest average irradiation only), and different levels of flooding (different water levels) in a vertically-oriented waste package. These calculations assume that the PWR fuel remains as emplaced in the waste package - i.e. they do not take into account any internal package degradation that could have occurred either before, or during, flooding of the package. Furthermore, it is assumed that the fuel channels within the package are inter-connected, so that the same water level is seen by all four fuel elements.

The results of a suite of MONK calculations to calculate $k_{\text {effective }}$ are summarized in Fig. 3 . This shows that critical configurations can only be achieved from flooding of the fuel package if the average fuel burn-up is $<\sim 35 \mathrm{GWd} / \mathrm{Te}$. For spent fuel with an average burn-up of $55 \mathrm{GWd} / \mathrm{Te}$, there is a significant safety margin from a critical configuration (i.e. $k_{\text {effective }}$ is $<1$ ) even if the package is fully flooded (corresponding to a mass of water of just above $150 \mathrm{~kg}$ per compartment). Furthermore, the safety margin increases as the cooling period, $T$, increases (i.e. as the peak value of $k_{\text {effective }}$ reduces). This clearly demonstrates that criticality is not possible for the configurations considered if the average fuel burn-up is sufficiently large.
In the bounding case where it is pessimistically assumed that the fuel has zero burn-up, Fig. 3 shows that the system could, hypothetically, become critical if the mass of water per compartment reached $\sim 12 \mathrm{~kg}$. Furthermore, as the mass of water increases (and therefore the flooded depth of the package increases), $k_{\text {effective }}$ continues to increase. For the flooding package, it is also possible to demonstrate that $k_{\text {effective }}$ will decrease with increasing temperature (Mason and Smith, $2015 b$ ). As a result, a rapid transient criticality is not possible, and only a QSS transient can be hypothesized, with $k_{\text {effective }}=1$ being maintained through continued flooding acting to increase $k_{\text {effective, while the temperature increase resulting }}$ from the heat of nuclear fission acts to decrease $k_{\text {effective }}$. Flooding of a PWR fuel package (of sufficiently low burn-up fuel) therefore provides a 'what-if' scenario for which the potential consequences of criticality can be considered.

\section{Analysis: criticality transients and the local consequences}

The QSS model has been developed for RWM as a powerful software tool to calculate the consequences of hypothetical post-closure criticality events. The model has undergone significant

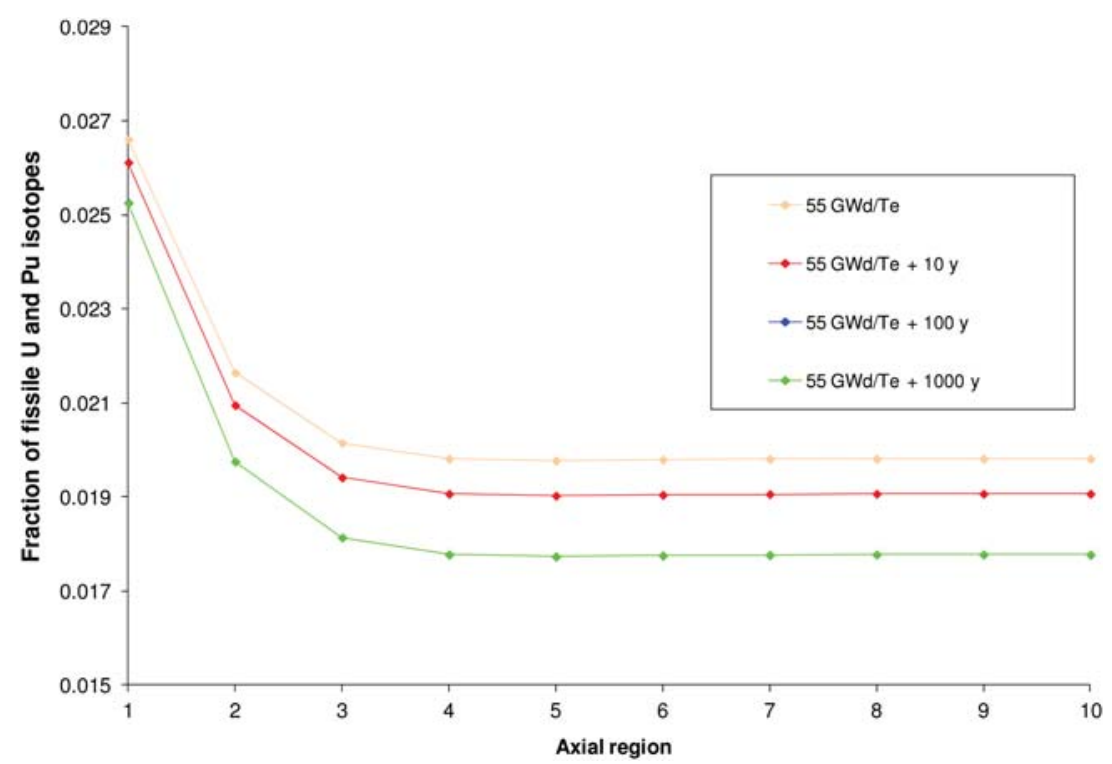

Fig. 2. Variation of the fraction of fissile uranium and plutonium nuclides at different levels of post-irradiation cooling. The curves for 100 and $1000 \mathrm{y}$ of cooling are very similar. 


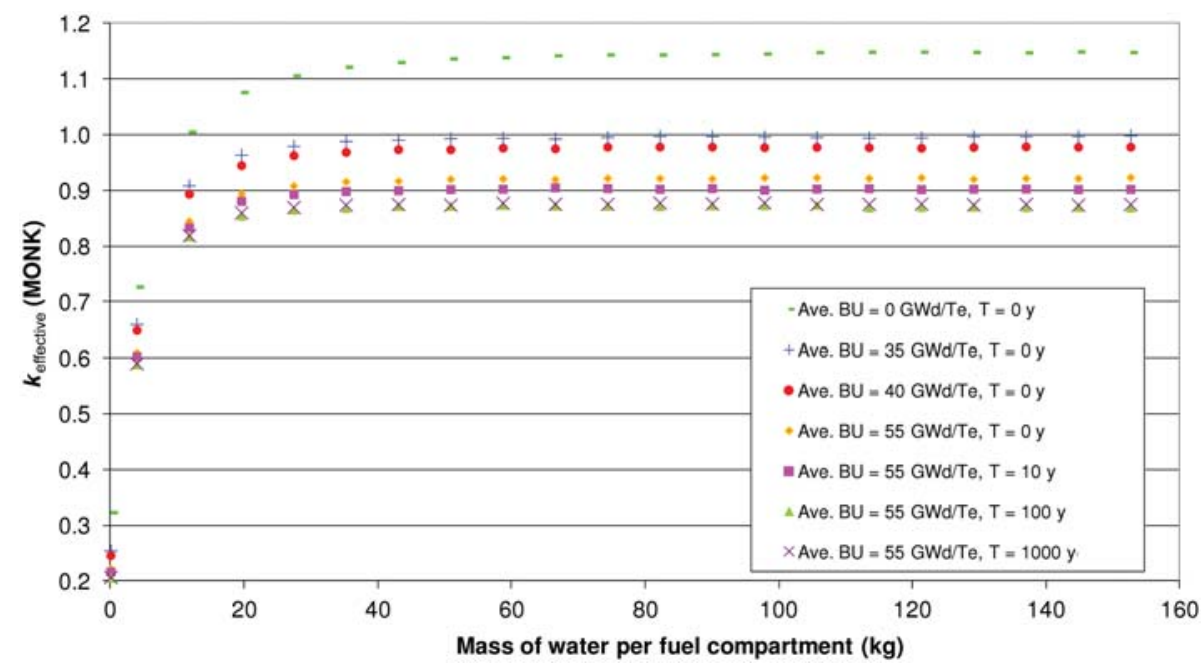

FIG. 3. Calculations of $k_{\text {effective }}$ as a function of water ingress into a spent PWR fuel disposal package for $5 \%$ enriched uranium dioxide fuel (initially) at different levels of burn-up. The average burn-up is given in $\mathrm{GWd} / \mathrm{Te}$, and the cooling period, $T$, is given in years where applicable.

testing that includes a successful comparison with the Oklo natural reactors where uranium deposits underwent nuclear fission $\sim 2$ billion years ago (at a time when natural uranium enrichment was $\sim 3.7 \%$ compared with the current $0.7 \%$ ) in what is now a region of Gabon in Africa (Mason et al., 2012b). In overview, once it has been established that an initially critical system would have a negative

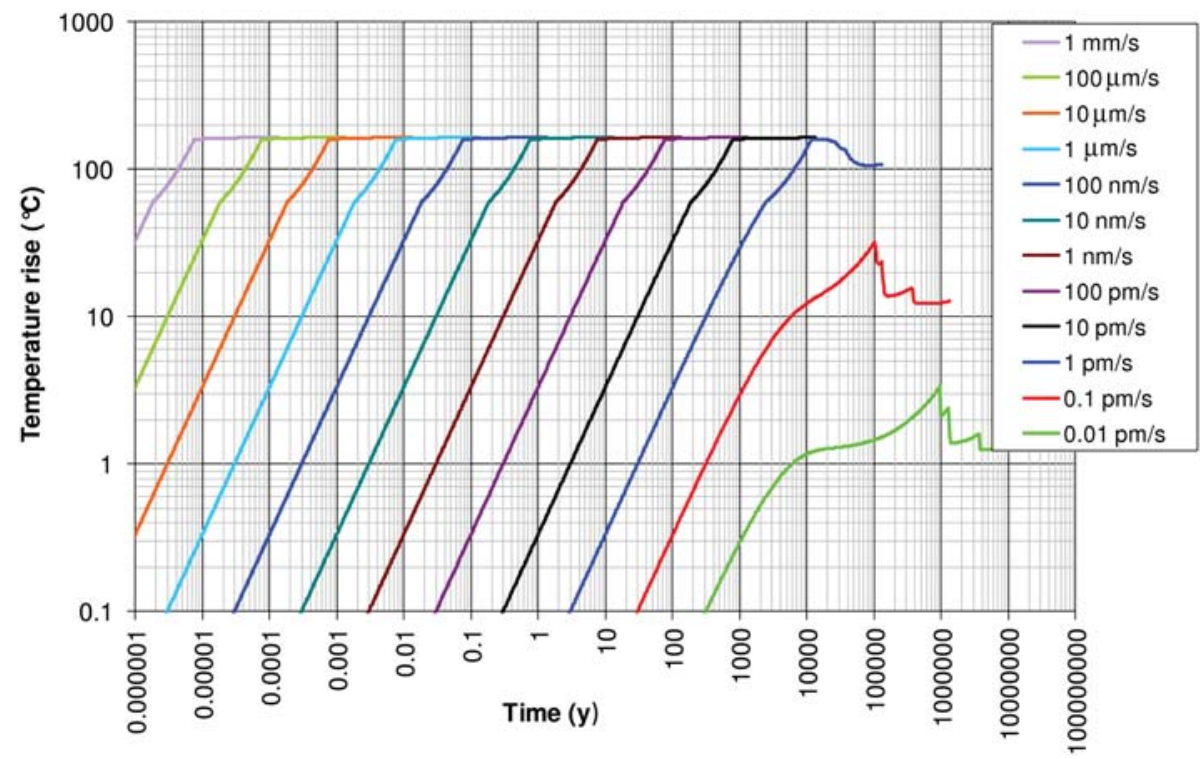

FIG. 4. Average temperature increase of the flooded region as a function of time for a QSS calculation of a flooding PWR fuel waste package. For the flooding rates $1 \mathrm{pm} / \mathrm{s}=10^{-12} \mathrm{~m} / \mathrm{s}$. The smallest flooding rate is equivalent to 14.3 M.y. to flood a $4.5 \mathrm{~m}$ waste package. The greatest flooding rate is equivalent to $1.25 \mathrm{~h}$ for flooding. 


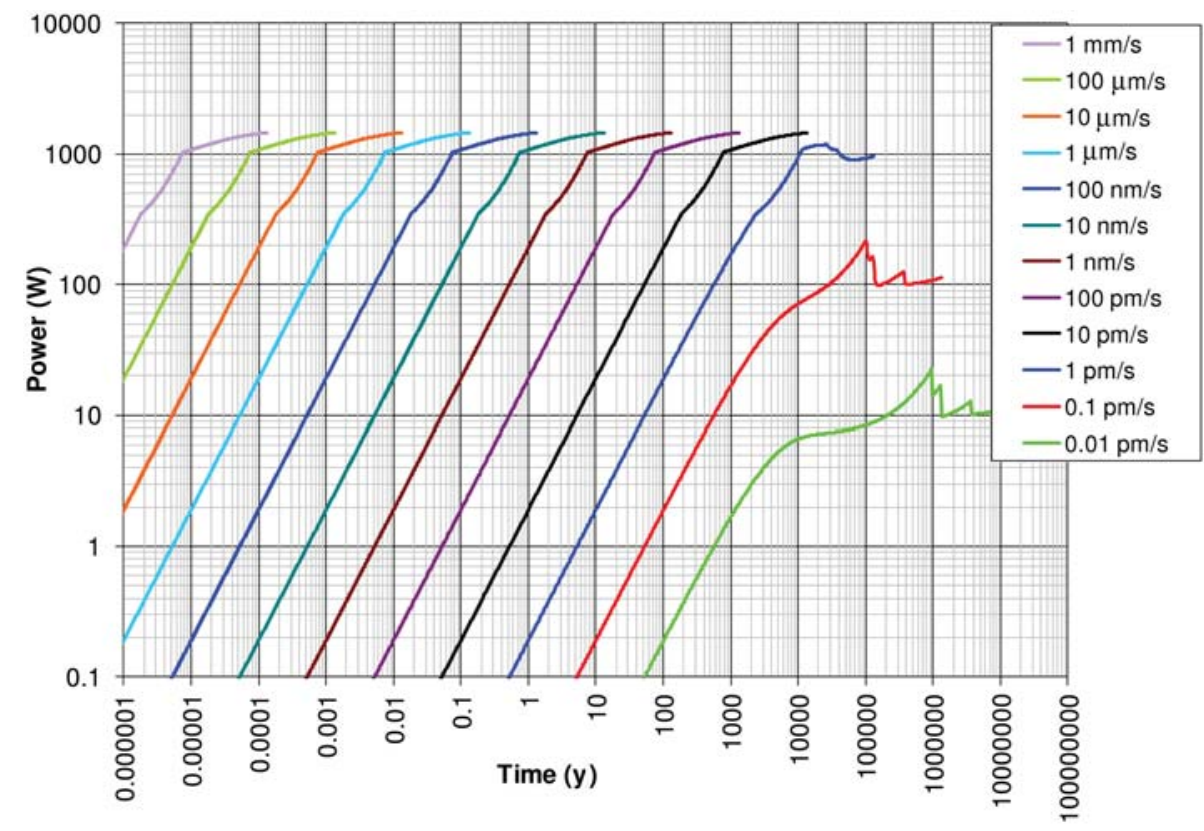

FIG. 5. Power as a function of time for a QSS calculation of a flooding PWR fuel waste package. Flooding rates as in Fig. 4.

temperature feedback, the QSS model requires user input to inform how $k_{\text {effective would vary }}$ with changes in temperature and the composition of the fissile material, including fission of isotopes such as ${ }^{235} \mathrm{U}$ and ${ }^{239} \mathrm{Pu}$, capture of neutrons in isotopes and radioactive decay. This is generally supplied as a multi-dimensional interpolated function of several variables. Coupled with models of heat transfer and the fission, capture and decay processes, the model can calculate how the temperature, power and composition of the system would evolve, while maintaining $k_{\text {effective }}=1$. Recently, new functionality has been added to the model to allow the geometry of the region undergoing nuclear fission to change with time (Smith and Mason, 2015). This new functionality has enabled a wider range of hypothetical postclosure criticality events to be considered, including that of a flooding waste package containing nuclear-reactor fuel (Mason et al., 2014; Mason and Smith, 2015a,b).

Using the just-critical mass of water from the zero burn-up curve in Fig. 3 (12 kg of water per fuel compartment) as the starting point, a range of calculations was undertaken using the QSS model for different flooding rates for water ingress into a waste package containing zero burn-up PWR fuel.
These range from an increased rate for the flooded height from as little as $10^{-14} \mathrm{~m} \mathrm{~s}^{-1}$ (which would take $>14$ million years to flood a package) to $1 \mathrm{~mm} \mathrm{~s}^{-1}$ (which would take $\sim 1.25 \mathrm{~h}$ ). Thermal properties of bentonite were used for heat transfer to the volume surrounding the critical region. The results for temperature increase and power are shown in Figs 4 and 5, respectively. These show that at all flooding rates of $10^{-12} \mathrm{~m} \mathrm{~s}^{-1}$ or greater, the temperature rise is $<170^{\circ} \mathrm{C}$ (corresponding to an actual temperature of $210^{\circ} \mathrm{C}$ ), and the power is $<1.5 \mathrm{~kW}$. The upper bound on temperature is clearly understood, as the temperature rise which balances the insertion of reactivity from flooding (i.e. offsets the rise in $k_{\text {effective }}$ to 1.15 as shown in Fig. 3 for fully flooded zero irradiation fuel at the ambient temperature). It is also noted that, even if larger temperature rises could occur, then there is an ultimate potential upper bound for temperature at $280^{\circ} \mathrm{C}$ in these QSS calculations (the assumed boiling point of water at a representative GDF depth and pressure). Should the groundwater boil then, with a low water (steam) density, it would not be possible to sustain a critical system, and the transient criticality would end. The calculated temperature and power for these hypothetical criticality events are not large enough to affect 
GDF performance, and hence demonstrate that the consequences of post-closure criticality are low.

\section{Comparison with other research}

The results of QSS calculations for hypothetical criticality events can usefully be compared with other research. A key observation is that the power generated in these hypothetical events is no greater than the power for which the waste packages are designed in the earlier stages of their life. In particular, the decay heat from PWR fuel packages due to fission product decay is also a few kilowatts. Hence a criticality event has no fundamental difference from decay heat in terms of heat generation rates.

Internationally, other waste-management organisations have undertaken modelling or analysis of the consequences of post-closure criticality for spent fuel. These range from simple energy-release calculations to modelling using similar arguments to the QSS model, although the scenarios for criticality also vary. A quantitative comparison of the available information is given by Mason et al. (2014) and concludes that where comparable analysis has been undertaken, the results are broadly in line with those of the QSS model, including temperature rises of no more than a few hundred degrees Celsius, and powers of the order of kilowatts.

\section{Conclusions}

This paper provides an overview of the research methodology undertaken to demonstrate that the consequences of hypothetical post-closure criticality events are low, with a focus on PWR spent fuel disposal. By understanding how criticality could arise, and applying a model to estimate the transient evolution of the criticality, the research supports the conclusion that post-closure criticality is not a significant concern for PWR spent fuel disposal because:

- If the burn-up of the spent fuel is large enough, it can clearly be demonstrated that criticality is not possible;

- For spent fuel with a low burn-up, even if a criticality event were to occur, it could only evolve as a quasi-steady-state where the temperature rise would be localized and the power comparable to the fission-product decay heat for which the packages are designed;
- The bentonite buffer would only be affected on a highly localized scale. Mass bentonite and geological properties would not be significantly affected by a criticality and would still act to isolate the radioactive waste from the surface environment.

In addition, direct radiation from the criticality event would be shielded by the surrounding rocks and materials and so is not a significant safety concern post-closure. The wider RWM research programme shows that the same conclusions also apply for other higher-activity radioactive wastes.

\section{Acknowledgements}

Useful discussions and inputs supporting this research are acknowledged: in particular from Lucy Bailey, Mike Poole, Peter Wood and Simon Wisbey (RWM), Colin Zimmerman (NNL) and Richard Cummings (LLWR).

\section{References}

Environment Agency, Northern Ireland Environment Agency (2009) Geological Disposal Facilities on Land for Solid Radioactive Wastes: Guidance on Requirements for Authorisation. Environment Agency, Northern Ireland Environment Agency.

Hicks, T.W. and Baldwin, T.D. (2014) Likelihood of Criticality: The Likelihood of Criticality Synthesis Report. AMEC Report to the Nuclear Decommissioning Authority, 17293-TR-022 Version 2.

Mason, R.M. and Smith, P.N. (2013) Modelling of consequences of hypothetical criticality: User guide for the rapid transient model and the bounding approach. AMEC Report to the Nuclear Decommissioning Authority, AMEC/SF2409/005 Issue 1.

Mason, R.M. and Smith, P.N. (2015a) Modelling of consequences of hypothetical criticality: Post-closure criticality consequence analysis for ILW, LLW and DNLEU disposal. AMEC Report to the Nuclear Decommissioning Authority, AMEC/SF2409/011 Issue 3.

Mason, R.M. and Smith, P.N. (2015b) Modelling of consequences of hypothetical criticality: Post-closure criticality consequence analysis for HLW, spent fuel, plutonium and HEU disposal. AMEC Report to the Nuclear Decommissioning Authority, AMEC/ SF2409/012 Issue 3.

Mason, R.M., Cummings, R., Kudelin, Y., Martindill, J., Smith, P.J. and Smith, P.N. (2009) A suite of calculations using the QSS and RTM computer models. Serco Report to the Nuclear Decommissioning Authority, SA/ENV-0944 Issue 2. 


\section{HYPOTHETICAL CRITICALITY FOR SPENT FUEL}

Mason, R.M., Cummings, R., Kudelin, Y., Martindill, J., Smith, P.J. and Smith, P.N. (2010) Further calculations using the QSS and RTM computer models. Serco Report to the Nuclear Decommissioning Authority, SERCO/TAS-1004 Issue 4.

Mason, R.M., Smith, P.N., Turland, B.D. and Jackson, C.P. (2012a) The consequences of hypothetical criticality. Mineralogical Magazine, 76, 3155-3163.

Mason, R.M., Martin, J.K., Smith, P.N. and Turland, B.D. (2012b) Comparison of a post-closure transient criticality model with the Oklo natural reactors. Mineralogical Magazine, 76, 3145-3153.

Mason, R.M., Smith, P.N. and Holton, D. (2014) Modelling of consequences of hypothetical criticality: Synthesis report for post-closure criticality consequence analysis. AMEC Report to the Nuclear Decommissioning Authority, AMEC/SF2409/013 Issue 2.

Newton, T., Hosking, G., Hutton, L., Powney, D., Turland, B. and Shuttleworth, T. (2008) Developments within WIMS10. PHYSOR Meeting, Interlaken, Switzerland.

Nuclear Decommissioning Authority (2010a) Geological Disposal: An Introduction to the generic Disposal System Safety Case. NDA Report no. NDA/RWMD/061.

Nuclear Decommissioning Authority (2010b) Geological Disposal: Generic Environmental Safety Case Main Report. NDA Report no. NDA/RWMD/030.

Nuclear Decommissioning Authority (2010c) Geological Disposal: Criticality Safety Status Report. NDA Report no. NDA/RWMD/038.

Richards, S.D., Baker, C.M.J., Bird, A.J., Cowan, P., Davies, N., Dobson, G.P., Fry, T.C., Kyrieleis, A. and Smith, P.N. (2014) MONK and MCBEND: Current Status and Recent Developments. Annals of Nuclear Energy, 82, 63-73. http://dx.doi.org/10.1016/j. anucene.2014.07.054

Smith, P.N. and Mason, R.M. (2015) Modelling of Consequences of Hypothetical Criticality: User Guide for the QSS Model. AMEC Report to the Nuclear Decommissioning Authority, AMEC/ SF2409/006 Issue 2.

Winsley, R.J., Baldwin, T.D., Hicks, T.W., Mason, R.M. and Smith, P.N. (2015) Understanding the likelihood and consequences of post-closure criticality in a geological disposal facility. Mineralogical Magazine, 79, DOI: 10.1180/minmag.2015.079.6.30 